Endocrinol. Japon. 1965, 12 (4), 249 261

\title{
STUDIES ON $\beta$-PAROTIN
}

\section{ISOLATION AND CHEMICAL PROPERTIES OF $\beta$-PAROTIN (STUDIES ON THE PHYSIOLOGICAL GHEMISTRY OF THE SALIVARY GLANDS LXVII*)}

\author{
YOSOJI ITO \\ Department of Physiological Chemistry, \\ Faculty of Pharmaceutical Sciences, University of Tokyo, Tokyo \\ SASHICHI OKABE AND SHUICHI NAMBA \\ Research Laboratory, Teikoku Hormone Mfg. Co., Ltd., Kawasaki
}

In the previous paper, it was reported that a protein, named $\beta$-parotin (Ito et al., $1965 \mathrm{a}$ ), having similar biological effects to salivary gland hormone (parotin) was detected in the autolyzed bovine parotid gland, and its extraction and purification were performed (Ito et al., 1965 b).

Furthermore, it was found that an inactive form of $\beta$-parotin obtained from intact parotid gland was easily converted into an active form by the definite incubation (Ito et al., $1965 \mathrm{c}$ ).

In this paper, some chemical properties of isolated $\beta$-parotin are described.

\section{EXPERIMENTS}

\section{Isolation procedure of $\beta$-parotin}

Crude $\beta$-parotin was obtained from the autolyzed bovine parotid gland and isolated by the procedure described in the previous paper. The flow sheet of extraction and purification is shown in Figure 1. The finally purified product prepared by these steps was designated as $\beta$ parotin.

The inactive form of $\beta$-parotin was prepared from intact parotid gland by the same procedure.

\section{Homogeneity of $\beta$-parotin}

The homogeneity of $\beta$-parotin was tested by both free boundary electrophoresis and ultracentrifugation. For electrophoresis following three buffers were used; veronal-sodium veronal ( $\mathrm{pH}$ 8.6, $\mu=0.1$ ), sodium monohydrogen phosphate-potassium dihydrogen phosphate ( $\mathrm{pH} 7.2$,

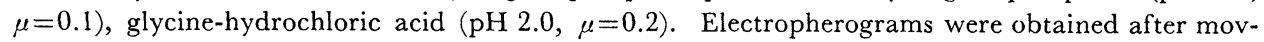
ing at 5 to $8 \mathrm{~mA}$ for 30 to 60 mins.. The ultracentrifugal analysis was carried out under the condition of 59,800 r.p.m. in phosphate buffer ( $\mathrm{pH} 7.6, \mu=0.2$ ).

Color reaction of $\beta$-parotin

In order to study the chemical characteristics of $\beta$-parotin, ninhydrin, millon and biuret

Received for publication June 7, 1965.

* LXVI : Ito, Y., S. Okabe and S. Namba (1965). Endcrinol. Japon. 12, 78. 


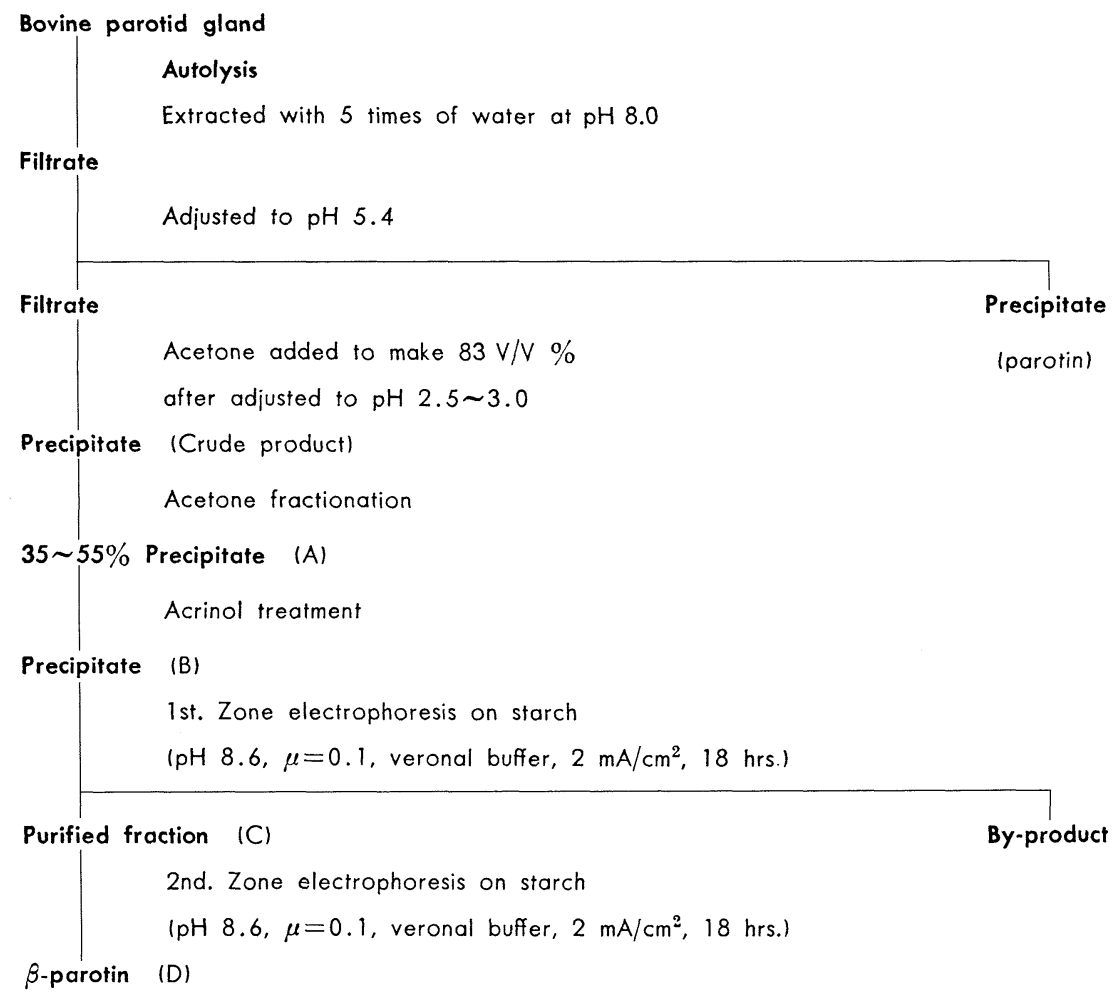

Fig. 1. Flow sheet of extraction and purification of $\beta$-parotin

color reactions were tried for protein analysis and Molisch, Elson-Morgan's reactions and the others were for carbohydrate analysis.

Amino acid composition

For the qualitative and quantitative analysis of amino acid composition of $\beta$-parotin, paper chromatographies were employed. Beta parotin was hydrolyzed in a sealed tube with a constant boiling hydrochloric acid at $110^{\circ} \mathrm{C}$ for $24 \mathrm{hrs}$.. The hydrolysate was subjected to two dimensional paper chromatography using the solvent system of n-burnnol +acetic acid + water (4:1:2), followed with phenol saturated with $0.1 \%(\mathrm{w} / \mathrm{v})$ ammonia. Each amino acid on the paper was qualitatively detected with ninhydrin reaction.

Furthermore, according to the method described by Levy (i954) amino acids in the hydrolysate were converted into DNP-amino acids by the reaction with dinitrofluorobenzene and separated with a two dimensional paper chromatography using the solvent system of butanol saturated with $0.1 \%(\mathrm{w} / \mathrm{v})$ ammonia followed with $1.5 \mathrm{M}$ phosphate buffer $(\mathrm{pH} 6.0)$ for ether soluble DNPamino acids, and a one dimensional paper chromatography using n-butanol + dioxane $+2 \mathrm{~N}$ ammonia $(8: 2: 3)$ for water soluble DNP-amino acids. The spots on the paper were cut out and extracted with $1 \%$ sodium bicarbonate at 55 to $60^{\circ} \mathrm{C}$ for 15 mins.. Three blanks also were cut out from the sheet. The determination of DNP-amino acids was carried out with the estimation of optical densities against the blank solution at $360 \mathrm{~m} \mu(385 \mathrm{~m} \mu$ in the case of DNP-proline) using a Beckman spectrophotometer.

The content of tryptophan was measured by the colorimetric method using p-dimethylamino- 
benzaldehyde according to the procedure of Spies and Chamber (1948) and by the ultraviolet absorption according to the method of Goodwin and Morton (1946). Tyrosine content was read at the same time.

Analysis of $N$-terminal amino acid

$\mathrm{N}$-terminal amino acid of $\beta$-parotin was determined with Sanger's dinitrophenylation method (DNP-method) and Edman's phenylisothiocyanate method (PTC-method).

In DNP-method, $20 \mathrm{mg}$ of sample was shaken with an excess dinitrofluorobenzene in $66 \%$ ethanol containing sodium bicarbonate. After hydrolysis with hydrochloric acid, the hydrolysate was extracted repeatedly with ether. The ether layer was analyzed with a two dimensional paper chromatography using the solvent system of butanol saturated with $0.1 \%(\mathrm{w} / \mathrm{v})$ ammonia, followed with $1.5 \mathrm{M}$ phosphate buffer. On the other hand, the aqueous layer was analyzed with an ascending one dimensional paper chromatography using n-butanol +acetic acid + water (4:1:2).

PTC-method was performed according to the procedure of Rovery et al. (1953); $20 \mathrm{mg}$ of sample was dissolved in 50\% dioxane and stirred with phenylisothiocyanate at $\mathrm{pH} 9.0$. The reaction mixture was extracted with cyclohexane and benzene, and the remaining aqueous solution was evaporated in vacuum. After hydrolysis with $\mathrm{N}$-hydrochloric acid at $100^{\circ} \mathrm{C}$ for 60 mins., the released amino acid hydantoin derivatives were chromatographed in the n-heptane + $\mathrm{n}$-butanol + formic acid $(2: 2: 1)$ and $\mathrm{n}$-heptane+pyridine $(7: 3)$ systems. The spots were visualized by the mixture of iodine and azide solutions.

\section{Analysis of C-terminal amino acid}

The C-terminal amino acid was determined by hydrazinolysis and carboxypeptidase methods.

In hydrazinolysis (Akabori et al., 1952), the sample was treated with an anhydrous hydrazine, and the reaction mixture was evaporated in vacuum. A small amount of water was added to the residue to be extracted with benzaldehyde. DNP method was applied on the remaining aqueous solution and the two dimensional paper chromatography of C-terminal DNP-amino acids was carried out in the same solvent system as that of $\mathrm{N}$-terminal amino acid.

Enzymatic method was performed by the procedure described by Glander and Neurath (1953) and by Fraenkel-Conrat et al. (1955). The specimen and bovine carboxypeptidase were incubated at $25^{\circ} \mathrm{C}$, pH 8.0 for 30 mins., $1 \mathrm{hr}$, 2 and 4 hrs. (weight ratio 50:1) ; carboxypeptidase was preincubated with diisopropylfuorophosphate (DFP). After the desired time intervals an aliquot was removed and mixed directly with a sulfonated polystyren ion exchanger (Amberlite IR-120, $\mathrm{H}^{+}$form, 15 30 mesh). The suspension containing the resin was then shaken mechanically for $1 \mathrm{hr}$., and the supernatant solution was removed; the resin beads were freely washed from protein with distilled water and amino acids were eluted from the resin with $5 \mathrm{~N}$ ammonia. The ammonia eluates were evaporated to dryness in vacuum over concentrated sulfuric acid, redissolved in the minimum volume of distilled water, and subsequently applied for one or two dimensional chromatography using n-butanol +acetic acid + water (4:1:2) and phenol saturated with $0.1 \%(\mathrm{w} / \mathrm{v})$ ammonia as the developing solvents. The chromatograms were sprayed with ninhydrin solution.

\section{Analysis of sugars}

1. Paper chromatographic analysis of sugar Beta parotin was hydrolyzed with $0.5 \mathrm{~N}$ sulfuric acid in a sealed tube at $105^{\circ} \mathrm{C}$ for $8 \mathrm{hrs}$.. After hydrolysis, sulfuric acid was removed as barium sulfate and the solution was evaporated to dryness in vacuum. One dimensional chromatography was carried out in s-collidine saturated with water and phenol containing $1 \%(\mathrm{w} / \mathrm{v})$ ammonia, and the carbohydrates were detected by silver nitrate-ammonia, aniline hydrogen phthalate and Ehrlich's reagent.

2. Quantitative analysis of hexose and hexosamine The hexose was measured by anthrone (Scott and Melvin, 1953) and carbazole methods (Seibert and Atno, 1946), using galactose as the referenced 
sugar. For hexosamine, the hydrolysate of $\beta$-parotin was determined by means of the modified Elson-Morgan method (Belcher et al., 1954), using glucosamine hydrochloride as the referenced sugar.

\section{RESULTS}

Through the purified steps of $\beta$-parotin, the yields and activities of each fraction are shown in Table 1 . About $50 \mathrm{mg}$ of $\beta$-parotin was obtained from $1 \mathrm{~kg}$
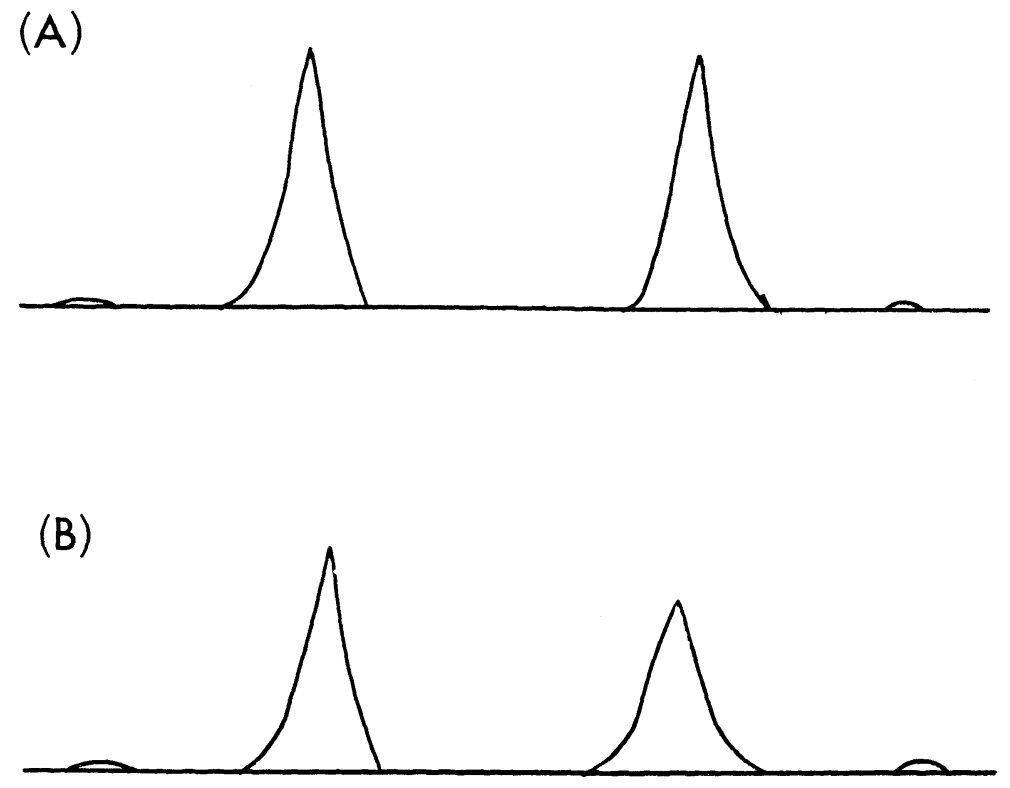

(C)

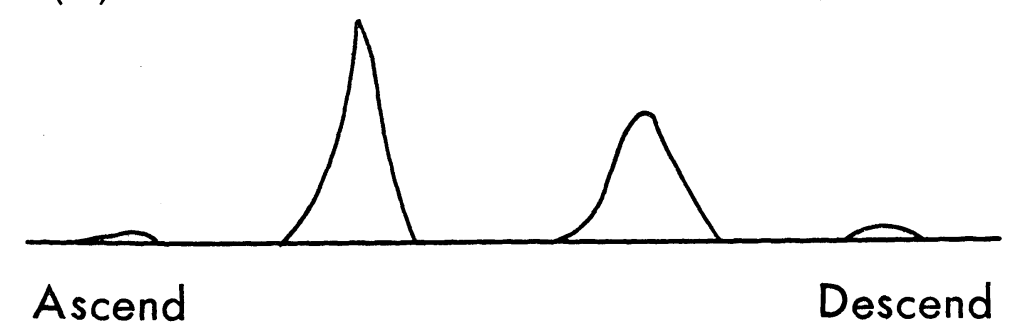

Fig. 2. Electrophoretic patterns of $\beta$-parotin

(A) $\mathrm{pH} 8.6, \mu=0.1$, veronal buffer, $5 \mathrm{~mA}, 35$ mins.

(B) $\mathrm{pH} 7.2, \mu=0.1$, phosphate buffer, $8 \mathrm{~mA}, 46$ mins.

(C) $\mathrm{pH} 2.0, \mu=0.2$, glycine buffer, $8 \mathrm{~mA}, 84$ mins. 


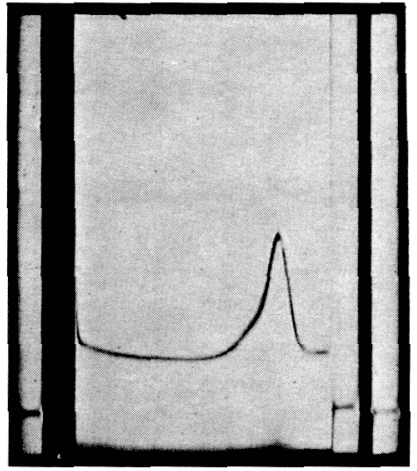

Fig. 3. Ultracentrifuge of $\beta$-parotin pH 7.6, $\mu=0.2$, phosphate buffer, 59,800 r.p.m., 48 mins.

Table 1. Yields and activities of each fraction in the purification steps of $\beta$-parotin

\begin{tabular}{|c|c|c|c|c|c|c|c|}
\hline \multirow{2}{*}{ Fraction } & \multirow{2}{*}{ Procedure } & \multicolumn{3}{|c|}{$\begin{array}{l}\beta \text {-Parotin } \\
\text { (from autolyzed gland) }\end{array}$} & \multicolumn{3}{|c|}{$\begin{array}{l}\text { Inactive } \beta \text {-Parotin } \\
\text { \{from intact gland) }\end{array}$} \\
\hline & & $\begin{array}{l}\text { Yield* } \\
\text { (g) }\end{array}$ & $\begin{array}{c}\text { Ca-activity }{ }^{\dagger} \\
(\mathrm{mg} / \mathrm{kg})\end{array}$ & L-activity $†$ & $\begin{array}{l}\text { Yield* } \\
\text { (g) }\end{array}$ & $\begin{array}{c}\text { Ca-activity } \dagger \\
(\mathrm{mg} / \mathrm{kg})\end{array}$ & L-activity ${ }^{\prime}$ \\
\hline \multicolumn{2}{|c|}{ Crude product } & 15.0 & 4.0 & + & 14.0 & $>8.0$ & - \\
\hline A & Acetone fractionation & 3.7 & 2.0 & + & 3.8 & $>4.0$ & - \\
\hline B & Acrinol treatment & 0.92 & 0.5 & + & 0.95 & $>1.0$ & - \\
\hline C & 1st. Zone electrophoresıs & 0.13 & 0.25 & + & 0.12 & $>1.0$ & - \\
\hline$D$ & 2nd. Zone electrophoresis & 0.05 & 0.25 & + & 0.04 & $>1.0$ & - \\
\hline
\end{tabular}

* Yields refer to $1 \mathrm{~kg}$ of bovine parotid gland.

†Biological activities were estimated using the hypocalcemic (Ca-activity) and leucocytosis producing (L-activity) tests (ito et al. 1965a)

Table 2. Color reactions of $\beta$-parotin*

\begin{tabular}{llll}
\hline \hline Reaction & + & Reaction & \\
\hline Ninhydrin & + & Phloroglucin-HCl & - \\
Biuret & + & Naphthoresorcin & - \\
Millon's & + & Bial's & - \\
Molisch's & + & Elson Morgan's & + \\
Anthron & + & & \\
\hline
\end{tabular}

*Active and inactive forms showed the same reactions.

of the bovine parotid gland. Between the yields of active and inactive forms of $\beta$-parotin, a significant difference was not observed.

The results of electrophoresis and ultracentrifugation are shown in Figures 2 and 3. It was shown that $\beta$-parotin was nearly homogeneous. 
Some color reactions of $\beta$-parotin are shown in Table 2. Beta parotin was found to be a glycoprotein containing hexose and hexosamine. The active and inactive forms of $\beta$-parotin showed the same color reactions.

\section{Amino acid composition}

The results of two dimensional paper chromatographies of amino acids and DNP-amino acids are shown in Figures 4 and 5 . The group containing valine and methionine could not be readily distinguished in Figure 4, and DNPmethionine was not detected in Figure 5. For the identification of isoleucine, the part of leucine in Figure 4 was cut out and extracted from the paper, and one dimensional paper chromatography was carried out using benzyl alcohol saturated with water. Tryptophan was identified by the methods of Spies and Chamber (1948), and of Goodwin and Morton (1946). It was confirmed that the commonly occurring 17 amino acids were present in $\beta$-parotin, only except methionine; cystine, aspartic acid, glutamic acid, serine, glycine, threonine, alanine, tyrosine, proline, valine, phenylalanine, leucine, lysine, histidine, arginine, isoleucine and tryptophan. Between the active and inactive forms of $\beta$-parotin, any significant difference was not observed qualitatively.

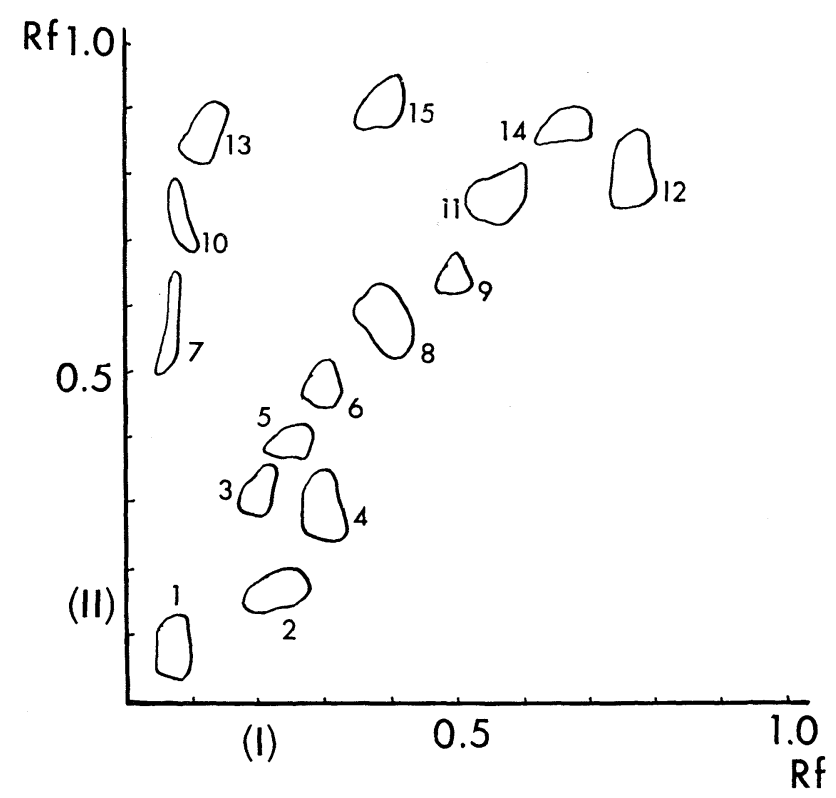

Fig. 4. Two dimensional paper chromatogram of $\beta$-parotin hydrolysate with hydrochloric acid

1. Cys., 2. Asp., 3. Ser., 4. Glu., 5. Gly., 6. Thr.,

7. Lys., 8. Ala., 9. Tyr., 10. His., 11. Val (Met).,

12. Leu (lleu)., 13. Arg., 14. Phe., 15. Pro.

Run in (I) n-butanol tacetic acid +water (4:1:2), and (II) phenol saturated with $0.1 \%$ ammonia 


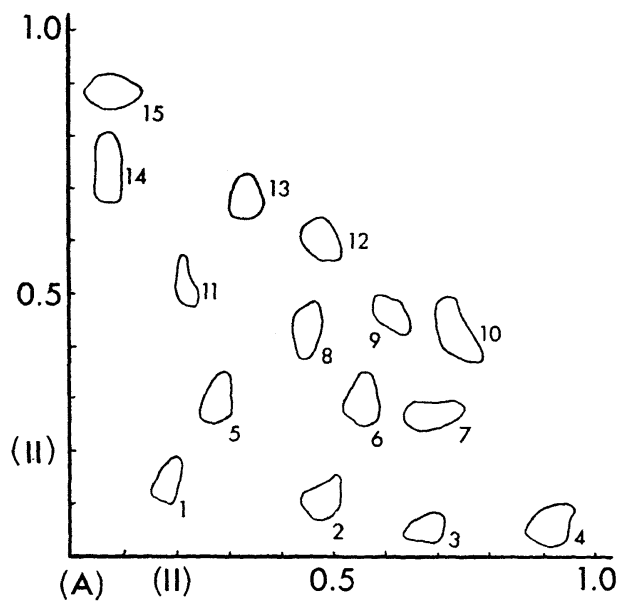

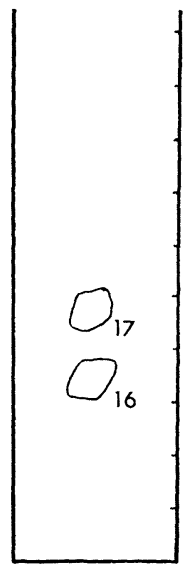

(B)

Fig. 5. Paper chromatograms of DNP-amino acid

(A) Ether soluble DNP amino acids. Run in (I) n-butanol saturated with $0.1 \%$ ammonia, and (II) $1.5 \mathrm{M}$ phosphate buffer

(B) Water soluble DNP amino acids. Run in n-butanol dioxane $+2 \mathrm{~N}$ ammonia $(8: 2: 3)$

1. Cys, 2. Lys, 3. Tyr, 4. DNP-NH 2 5. Gly, 6. DNP-OH, 7. Phe, 8. Ala,

9. Val, 10. Leu (lleu), 11. Ser, 12. Pro, 13. Thr, 14. Glu, 15. Asp, 16.

Arg, 17. His

Table 3. Amino acid content in active and inactive $\beta$-parotin

\begin{tabular}{ccc}
\hline Amino acid & $\beta$-Parotin & Molar-ratio \\
\hline Asp & 100 & 100 \\
Glu & 89.5 & 98.3 \\
Thr & 65.4 & 78.5 \\
Ser & 57.3 & 65.2 \\
Ala & 45.5 & 51.6 \\
Arg & 30.5 & 31.6 \\
Pro & 30.1 & 34.2 \\
Gly & 25.5 & 28.0 \\
Tyr & 23.6 & 31.7 \\
Cys & 20.8 & 24.5 \\
Val & 15.8 & 25.5 \\
Phe & 15.5 & 18.7 \\
His & 15.3 & 20.3 \\
Leu (lleu) & 13.6 & 20.5 \\
Lys & 13.4 & 25.3 \\
\hline Try (\%) & $1.03^{*}$ & $1.11^{*}$ \\
& $0.81^{* *}$ & $0.87^{* *}$ \\
\hline
\end{tabular}

* p-Dimethylaminobenzaldehyde method

**U.V.-absorption method 
The molar ratio of constituent amino acids of $\beta$-parotin was roughly determined from the optical densities of yellow DNP-derivatives. Table 3 shows the molar ratio of amino acids referred to a base of aspartic acid $(=100)$. Some differences were observed between the active and inactive forms of $\beta$-parotin as to the molar ratio of amino acids. In either form, however, the order of the molar concentration of amino acid tended to be similar to each other except a few cases. The content of tryptophan was a little.

\section{Terminal amino acids of $\beta$-parotin}

The chromatogram of ether soluble DNP-amino acid released with acid hydrolysis of DNP $\beta$-parotin is shown in Figure 6. The spot of DNP aspartic acid was distinctly detected on the paper, indicating the $\mathrm{N}$-terminal amino acid. In the water soluble fraction, on the other hand, only $\varepsilon$-DNP lysine was detected.

The chromatograms of amino acid phenylthiohydantoins liberated from $\beta$ parotin by PTG-method are shown in Figure 7. When n-heptane+pyridine was used as the solvent, a distinct spot of aspartic acid derivative and an indistinct spot corresponding to phenylalanine derivative were found. In the solvent system of $n$-heptane + n-butanol + formic acid, only distinct spot of aspartic acid derivative was detected.

From these results, the $\mathrm{N}$-terminal amino acid of $\beta$-parotin was demonstrated as aspartic acid.

The result of paper chromatography of C-terminal DNP amino acids obtained

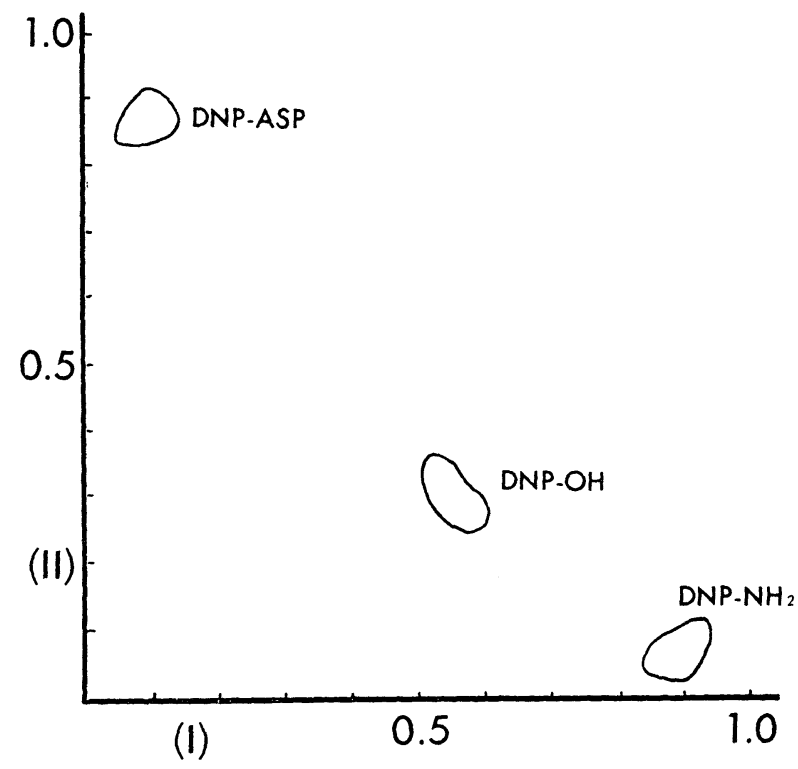

Fig. 6. Cinromatogram of $\mathrm{N}$-terminal amino acid released from $\beta$-parotin Run in (I) $r$-butanol saturated with $0.1 \%$ ammonia, and

(II) $1.5 \mathrm{M}$ phosphate buffer 


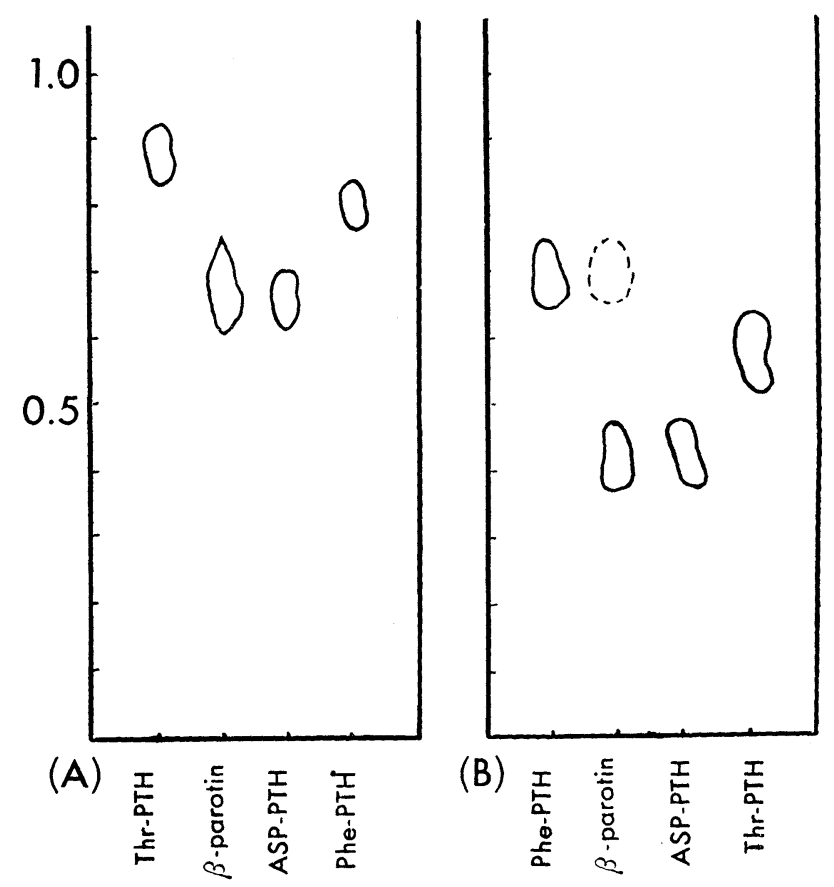

Fig. 7. Chromatogram of amino acid phenylthiohydantoins (PTH) liberated from $\beta$-parotin by PTC-method

Run in (A) n-heptane+n-butanol +formic ccid $(2: 2: 1)$, and (B) n-heptane tpyridine $(7: 3)$

Sprayed with a mixture of iodine and azide solutions

by hydrazinolysis is shown in Figure 8. Two distinct spots of DNP-alanine, DNP-serine and an indistinct spot corresponding to DNP-phenylalanine were detected.

The results of the analysis of C-terminal residues using carboxypeptidase are shown in Figure 9. Figure 9-A shows chromatogram of the referenced known amino acids and of the unknown amino acids which were liberated by the enzyme. After the incubation for 30 mins. and $1 \mathrm{hr}$., serine and alanine were found, and after 2 hrs. leucine appeared, but phenylalanine was not liberated. The two dimensional paper chromatogram of amino acids released with carboxypeptidase by the incubation for $4 \mathrm{hrs}$. is shown in Figures 9-B. Although serine, alanine and leucine were found, C-terminal amino acids of $\beta$-parotin were probably both of alanine and serine, because of a practical lag in the appearance of leucine.

Analysis of carbohydrate component of $\beta$-parotin

It was supposed from color reactions that some carbohydrate components might be contained in $\beta$-parotin. Thus the paper chromatographies of acid hydrolysates of $\beta$-parotin were performed using s-collidine saturated with water 


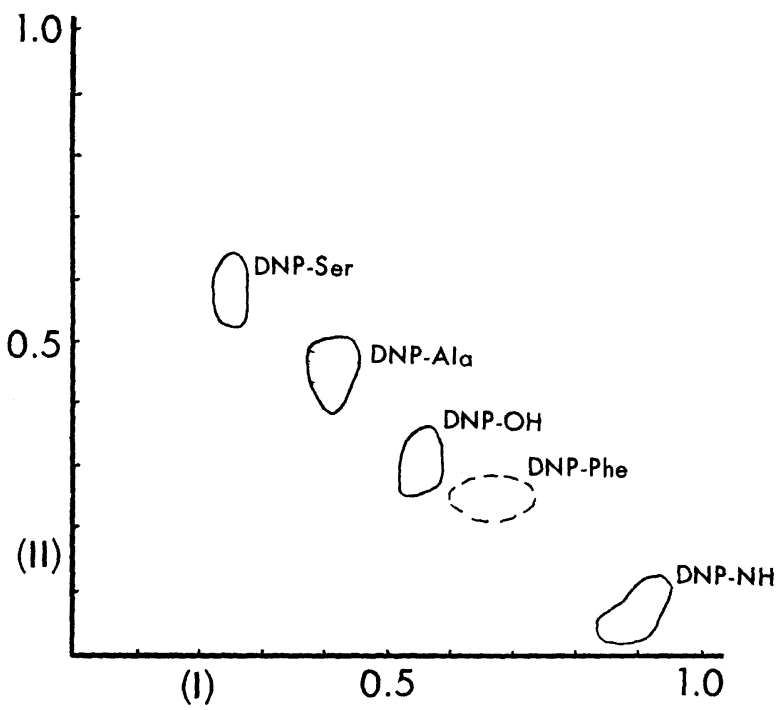

Fig. 8. Chromatogram of C-terminal DNP-amino acids released from $\beta$-parotin by hydrazinolysis

Run in (I) n-butanol saturated with $0.1 \%$ ammonia, and $1.5 \mathrm{M}$ phosphate buffer

Rf

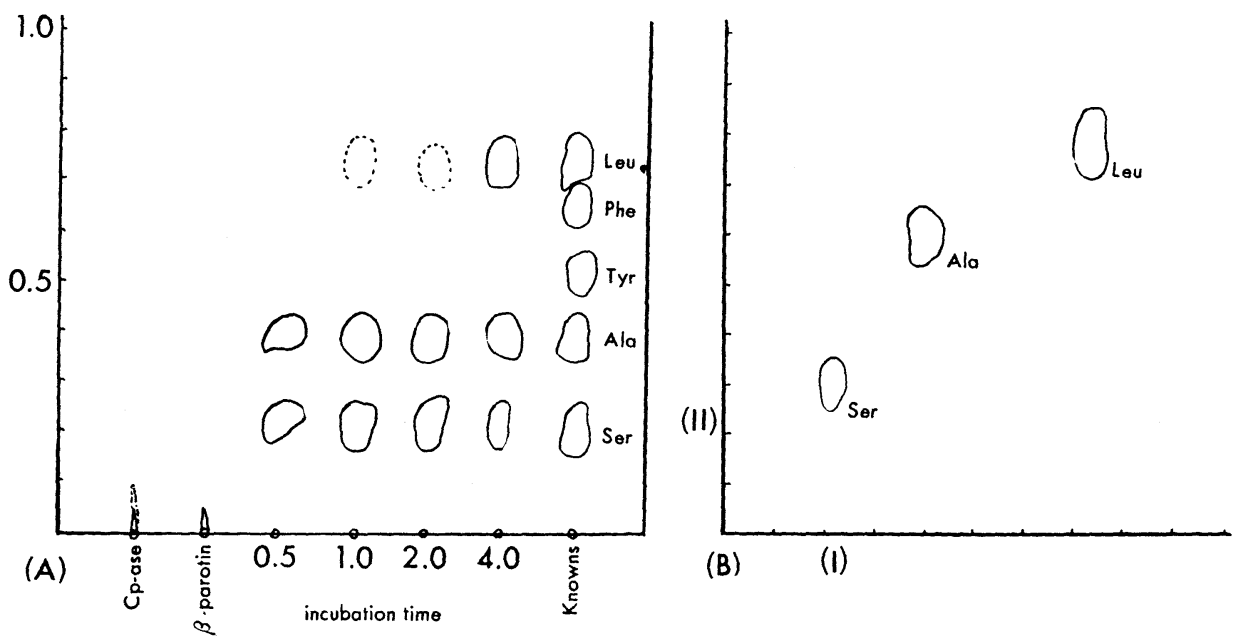

Fig. 9. Chromatograms of C-terminal amino acid liberated from $\beta$-parotin by enzymatic method, sprayed, with ninhydrin solution

(A) One dimensional chromatogram: Run in $n$-butanol tacetic acid + water $(4: 1: 2)$

(B) Two dimensional chromatogram (after incubation for $4 \mathrm{hrs}$ ): Run in (I) n-butanol tacetic acid twater (4:1:2), and (II) phenol saturated with $0.1 \%$ ammonia 

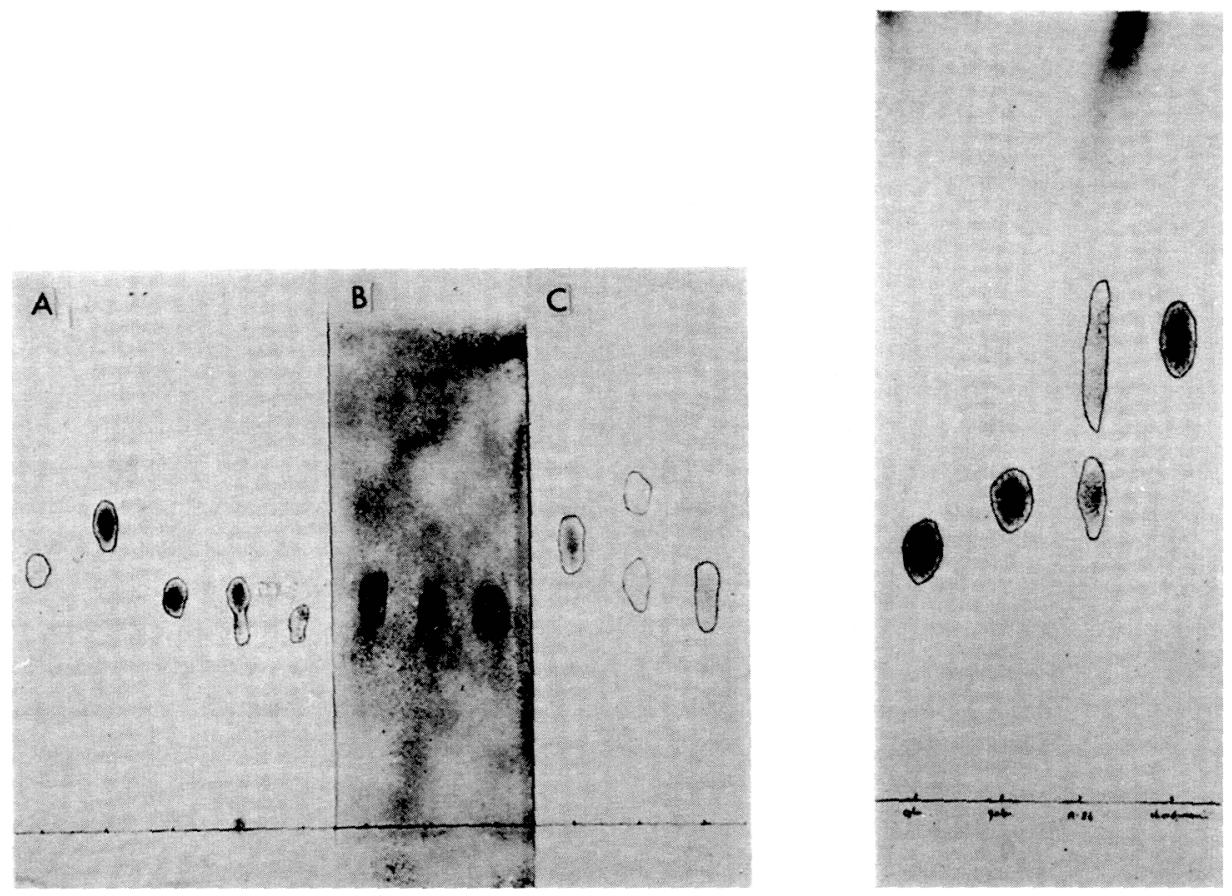

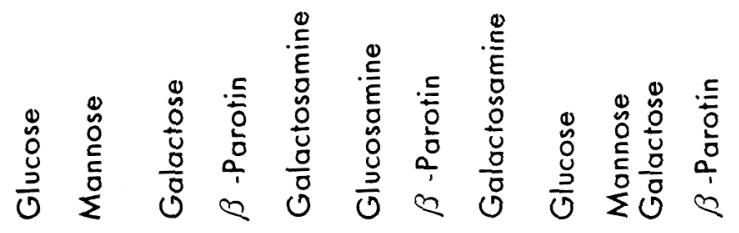

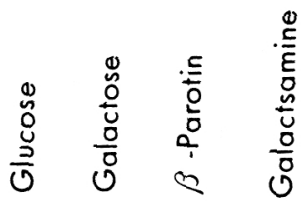

Fig. 10. Chromatograms of sugars from $\beta$-parotin (1) Run in s-collidine-water, sprayed with
(A) silver nitrate-ammonia
(B) Ehrlich's reagent
(C) aniline hydrogen phthalate

Fig. 11. Chromatogram of sugars from $\beta$-parotin (II) Run in phenol containing $1 \%$ ammonia, sprayed with silver nitrate-ammonia

Table 4. Hexose and hexosamine contents of $\beta$-parotin

\begin{tabular}{llcl} 
& Method & $\beta$-Parotin & Inactive $\beta$-Parotin \\
\hline Hexose $(\%)$ & Anfhron & 2.6 & 2.4 \\
& Carbazole & 2.4 & 2.1 \\
\hline
\end{tabular}

or phenol containing $1 \%$ ammonia. These results are shown in Figures 10 and 11. Beta parotin was a glycoprotein containing galactose and hexosamine. The 
same results were obtained in the inactive form of $\beta$-parotin.

These sugars were quantitatively determined by means of the colorimetric method. The results are shown in Table 4; the contents of hexose and hexosamine were about $2.5 \%$ and $0.5 \%$ respectively, and no difference was observed between the active and inactive forms of $\beta$-parotin.

\section{DISCUSSION}

It was clarified that 17 amino acids were present in $\beta$-parotin, and comparing with parotin, methionine was absent. The $\mathrm{N}$-terminal amino acid residue was only aspartic acid. On the other hand, it has been reported by Kubota (1960) that the $\mathrm{N}$-terminal amino acids of parotin are alanine, glycine and aspartic acid. The C-terminal amino acids of $\beta$-parotin were demonstrated as alanine and serine.

Before the analysis of carbohydrate components, $\beta$-parotin was treated with cation exchanger to remove a trace of starch probably contaminated by zone electrophoretical purification step; $\beta$-parotin was adsorbed to Amberlite XE-64 in citrate buffer ( $\mathrm{pH} 3.0, \mu=0.06$ ) and the resin was sufficiently washed with the buffer, and then $\beta$-parotin was eluted from the resin with phosphate buffer $(\mathrm{pH}$ $6.7, \mu=0.6$ ). Ito (1954) has reported that parotin contains only slight mannose as carbohydrate component. From the results of the present experiment, however, $\beta$-parotin contains about $2.5 \%$ of galactose and a small quantity of hexosamine. Thus a significant difference was observed between $\beta$-parotin and parotin. Other parotin-like substances- $\alpha$-parotin (Asano, 1961) from bovine parotid gland and uroparotin (Yamamoto, 1960) from urine-have been also reported to be glycoproteins. In these parotin-like substances and parotin, a relation between sugar components and physiological properties is not clarified yet.

\section{SUMMARY}

Amino acid composition, terminal amino acid residues and carbohydrate components were analyzed for purified $\beta$-parotin. Seventeen amino acids, except methionine comparing with parotin, were found in $\beta$-parotin and $N$-terminal amino acid was aspartic acid. C-terminal amino acids of $\beta$-parotin were alanine and serine, and $\beta$-parotin was considered to be a glycoprotein containing hexose and hexosamine.

Qualitatively, no difference between active and inactive forms of $\beta$-parotin was found out in the amino acid and carbohydrate composition.

\section{REFERENGES}

Akabori, S., K. Ohno and K. Narita (1952). Bull. Chem. Soc. Jafian 25, 214.

Asano, H. (1961). Endocrinol. Japon. 8, 199.

Belcher, R., A.T. Nutten and C.M. Samlorook (1954) Analyst 79, 201.

Fraenkel-Conrat, J., I. Harris and A.L. Levy. Methods of Biochemical Analysis 2, Interscience Publishers, New York, P. 359 (1955).

Glander, J.A. and H. Neurath (1953). J. Biol. Chem. 205, 345. 
Goodwin, T.W. and R.A. Morton (1946). Biochem. J. 40, 628.

Ito, Y. (1954). Endocrinol. Japon. 1, 1.

Ito, Y., S. Okabe and S. Namba (1965a). Ibid. 12, 63.

Ito, Y., S. Okabe and S. Namba (1965b). Ibid. 12, 69.

Ito, Y., S. Okabe and S. Namba (1965c). Ibid. 12, 78.

Kubota, Y. (1960). Ibid. 7, 175.

Levy, A.L. (1954). Nature 174, 126.

Rovery, M., C. Fabre and P. Desnuelle (1953). Biochim. et Biophys. Acta 12, 547.

Scott, T.A. and E.H. Melvin (1953). Anal. Chem. 25, 1656.

Seibert, F.B. and J. Atno (1946). J. Biol. Chem. 163, 511.

Spies, J. and R. Chamber (1948). Anal. Chem. 20, 30.

Yamamoto, M. (1960). Endocrinol. Japon. 7, 76. 